\title{
RETINOBASE: a web database, data mining and analysis platform for gene expression data on retina Ravi Kiran Reddy Kalathur ${ }^{1}$, Nicolas Gagniere ${ }^{1}$, Guillaume Berthommier ${ }^{1}$, Laetitia Poidevin ${ }^{1}$, Wolfgang Raffelsberger ${ }^{1}$, Raymond Ripp ${ }^{1}$, Thierry Léveillard ${ }^{2}$ and Olivier Poch*1
}

Address: ${ }^{1}$ Laboratoire de Bioiformatique et de Genomique Integratives, Institut de Génétique et de Biologie Moléculaire et Céllulaire, CNRS/ INSERM/ULP, BP 163, 67404 Illkirch Cedex, France and 'Inserm U592 Universite Pierre et Marie Curie, Laboratoire de Physiopathologie Céllulaire et Moléculaire de la Retine, Hopital Saint-Antoine, Paris, France

Email: Ravi Kiran Reddy Kalathur - ravi@igbmc.u-strasbg.fr; Nicolas Gagniere - gagniere@igbmc.u-strasbg.fr; Guillaume Berthommier - berthomg@igbmc.u-strasbg.fr; Laetitia Poidevin - Laetitia.Poidevin@igbmc.u-strasbg.fr; Wolfgang Raffelsberger - wraff@igbmc.u-strasbg.fr; Raymond Ripp - ripp@igbmc.u-strasbg.fr; Thierry Léveillard - Thierry.Leveillard@stantoine.inserm.fr; Olivier Poch* - poch@titus.u-strasbg.fr

* Corresponding author

Published: 5 May 2008

BMC Genomics 2008, 9:208

doi:I0.|I86/|47|-2164-9-208
Received: 30 October 2007

Accepted: 5 May 2008

This article is available from: http://www.biomedcentral.com/147I-2164/9/208

(c) 2008 Kalathur et al; licensee BioMed Central Ltd.

This is an Open Access article distributed under the terms of the Creative Commons Attribution License (http://creativecommons.org/licenses/by/2.0), which permits unrestricted use, distribution, and reproduction in any medium, provided the original work is properly cited.

\begin{abstract}
Background: The retina is a multi-layered sensory tissue that lines the back of the eye and acts at the interface of input light and visual perception. Its main function is to capture photons and convert them into electrical impulses that travel along the optic nerve to the brain where they are turned into images. It consists of neurons, nourishing blood vessels and different cell types, of which neural cells predominate. Defects in any of these cells can lead to a variety of retinal diseases, including age-related macular degeneration, retinitis pigmentosa, Leber congenital amaurosis and glaucoma. Recent progress in genomics and microarray technology provides extensive opportunities to examine alterations in retinal gene expression profiles during development and diseases. However, there is no specific database that deals with retinal gene expression profiling. In this context we have built RETINOBASE, a dedicated microarray database for retina.

Description: RETINOBASE is a microarray relational database, analysis and visualization system that allows simple yet powerful queries to retrieve information about gene expression in retina. It provides access to gene expression metadata and offers significant insights into gene networks in retina, resulting in better hypothesis framing for biological problems that can subsequently be tested in the laboratory. Public and proprietary data are automatically analyzed with 3 distinct methods, RMA, dChip and MAS5, then clustered using 2 different K-means and I mixture models method. Thus, RETINOBASE provides a framework to compare these methods and to optimize the retinal data analysis. RETINOBASE has three different modules, "Gene Information", "Raw Data System Analysis" and "Fold change system Analysis" that are interconnected in a relational schema, allowing efficient retrieval and cross comparison of data. Currently, RETINOBASE contains datasets from 28 different microarray experiments performed in 5 different model systems: drosophila, zebrafish, rat, mouse and human. The database is supported by a platform that is designed to easily integrate new functionalities and is also frequently updated.
\end{abstract}

Conclusion: The results obtained from various biological scenarios can be visualized, compared and downloaded. The results of a case study are presented that highlight the utility of RETINOBASE. Overall, RETINOBASE provides efficient access to the global expression profiling of retinal genes from different organisms under various conditions. 


\section{Background}

The retina is a thin and highly structured layer of neuronal cells that lines the back of eye. Its main function is to convert light energy into an interpretable signal for cortical cells in the brain. The retina has two components - an inner neurosensory retina and an outer retinal pigment epithelium (RPE), which together form the structural and functional basis for visual perception.

The retina consists of several cell types, of which neural cells predominate. Photoreceptors, bipolar and ganglion cells are three principal neuron cell types whose activity is modulated by other groups of cells, such as horizontal and amacrine cells [1]. Defects in any of the above-mentioned cell types can lead to a variety of retinal diseases, including age-related macular degeneration (AMD), retinitis pigmentosa (RP), Leber congenital amaurosis (LCA) and glaucoma. These diseases may cause partial visual loss or complete blindness, depending on the severity.

The recent progress in genomic approaches has now led to an increase in the number of transgenic and knockout animal models that can be used to investigate the role of specific genes in retinal function and related disorders in humans, e.g., rd1 is a mouse model for RP [2], Nr2e3 for the Human Enhanced S-cone syndrome (ESCS) [3], Rds for macular dystrophy and RPE65\%-for LCA [4]. Experimental information from the above mentioned models, combined with high-throughput technologies, has led to an increase in the number of experiments related to retinal gene expression.

The recent development of high-throughput technologies has resulted in an enormous volume of gene expression data. General repositories such as GEO [5] and ArrayExpress [6] operate as central data distribution centres encompassing gene expression data from different organisms and from various conditions. In contrast, resources like CGED [7], SIEGE [8] and GeneAtlas [9] are specialized databases that address specific problems; CGED concentrates on gene expression in various human cancer tissues, SIEGE focuses on epithelial gene expression changes induced by smoking in humans and Gene Atlas provides the expression profiles of genes in various mouse and human tissues.

In order to address specific issues related to retina and to meet the needs of retinal biologists in their analysis of gene expression data, we have developed RETINOBASE, a microarray gene expression database for retina. RETINOBASE combines simplified querying, analysis and data visualization options, plus specifically developed meta analysis tools. The integration of gene expression data from various development stages of wild type retina and from diverse conditions and genetic backgrounds will hopefully, not only increase our understanding of the physiological mechanisms involved in normal retinal tissue, but also facilitate studies of gene expression patterns under diverse conditions. Furthermore, RETINOBASE provides a platform for the comparison of different analysis scenarios based on various normalization methods, such as RMA [10], dChip [11], MAS5 [12], and clustering methods, such as the K-means [13] and mixture models methods [14].

\section{Construction and content}

RETINOBASE uses open-source tools. The website is powered by an Apache web server, PHP and Javascript for dynamic web pages and a PostgreSQL object-relational open source database management system (DBMS) as the back end to store data. The RETINOBASE database schema has been developed using the same philosophy as that used to design BASE [15], with enhancements to accommodate data from different platforms and also complies to the Minimum Information About Microarray Experiment (MIAME) standard [16]. It is based on a welldesigned relational schema where "realexp" acts as a central table linking expression data with an experiment, sample and array type. This kind of schema helps the system to manage data efficiently, and increases retrieval speed.

RETINOBASE is designed to store gene expression profiles from microarray experiments. We downloaded all publicly available retina-related expression profiles from Gene Expression Omnibus (GEO) yielding 21 experiments [17-32], GEO datasets (GSE 1816, 4756, 1835, $3791,2868)$. In addition, 8 proprietary experiments have been incorporated that can be accessed with permission from the owner of the experiment. These experiments were performed under different conditions, including knockout models, treatments and time series experiments performed on different organisms such as drosophila, zebra fish, rat, mice and human. All experiments have complete data, except for one experiment [19] that has partial data at the level of fold change, due to the unavailability of raw data (.CEL) or signal intensity data. Currently, RETINOBASE contains approximately 27 million gene expression values resulting from 509 hybridizations. In future releases of the database, we plan to include data from other studies associated with retina, including the SAGE [33], datasets from Diehn and coworkers [34] who used cDNA array to study human eye tissues, and/or datasets from Blackshaw and coworkers [35] who used SAGE to study mouse retinal development.

\section{Gene information}

In RETINOBASE, the gene annotation information obtained from Affymetrix [36] is linked to information about genes and loci causing inherited retinal diseases, 
obtained from the Retinal information network (RETNET) [37]. RETINOBASE also provides information obtained from literature about expression of approximately 200 retinal genes specific to certain types of cell, such as photoreceptors, Muller cells or retinal sphere cells.

\section{Data information}

Raw data was obtained in two different formats, either as .CEL files (20 experiments) or at the level of signal intensities (8 experiments). Data obtained at the level of .CEL files are first analysed with three different normalization programs - RMA [10], dChip [11] and MAS5 [12] and then processed using the $\mathrm{R}$ statistical package [38] and Bioconductor [39]; after preprocessing, the resulting background-corrected and normalized signal intensities are automatically uploaded to RETINOBASE using SQL scripts via pgAdminIII.

Identification of control samples in an experiment facilitated incorporation of data at the level of fold change in RETINOBASE. The fold-changes in gene expression were calculated as the ratio between the signal intensities of a given gene in the treated (or knockout) model and the control. In the case of experiments performed in replicate, signal intensities were averaged before calculation of the ratios. All the experiments in RETINOBASE were clustered using 3 independent methods: (i) the density of points clustering (DPC) method [40] which is implemented in the in-house FASABI (Functional And Statistical Analysis of Biological Data) software, (ii) the dot product K-means method [41] used in TM4 Multiexperiment Viewer (MeV) a free, open-source system for microarray data management and analysis [42], (iii) the mixture model method implemented in FASABI. Although cluster analyses often provide useful insights into the data, biological interpretation of the results is recommended, since alternative algorithms generally produce different cluster outputs and no single clustering algorithm is best suited for clustering genes into functional groups for all data sets [43]. We chose the DPC, K-means and mixture models methods because of their robustness in clustering large datasets. Although the K-means method generally requires the user to choose the number of clusters to be calculated, the TMEV system uses figure of merit (FOM) graphs [44] to make an appropriate suggestion. Other clustering algorithms, such as a graph-theoretic approach [45], and a neural network based method SOM [46], as well as different parameter options, will be incorporated in future releases of the database. Storing both the normalized and analyzed data in our relational model allows flexible comparisons across different chips at the level of individual genes.

\section{Quality control}

Quality control reports are generated using affyQCReport - an R package that generates quality control reports for Affymetrix array data [47] and RReportGenerator [48] for all experiments, where .CEL files are available. In addition, we also calculate a coefficient of variation for individual Probe Sets between the replicates, which provides a direct estimate of the quality between replicates.

\section{Experiment and sample details}

The RETINOBASE home page presents a list of all experiments available to the user and also provides access to experimental details such as title, short description etc. The "Sample details" option (Figure 1) gives details about sample description, organism, tissue, treatment, strain specific information and the array used for hybridisation for a given experiment.

\section{Querying the database}

RETINOBASE has three different querying modules: "Gene Information", "Raw Data System Analysis" and "Fold change system Analysis".

\section{Gene information module}

The "Gene Information" module offers three different query options - "Gene Query", "Ortholog Query" and "Blast Query". Using these, one can access information such as chromosomal location, linked retinal diseases, cellular localization, and gene ontologies for a given gene. Furthermore, gene details returned from these queries are linked to external databases such as GeneCards [49], NCBI [50], specifically to UniGene [51], ADAPT mapping viewer [52] and also to UCSC genome browser [53] that would yield more information (Figure 2).

"Gene Query" and "Ortholog Query" accept as input the gene name, symbol, Affymetrix Probe Set ID, Refseq or Unigene IDs, whereas "Blast Query" accepts sequences in FASTA format. "Ortholog Query" is useful in cross-referencing probe sets between different Affymetrix GeneChip arrays. The data based on reference sequence similarity is taken from HomoloGene and cross-referenced. In addition, the raw data and cluster information for a given gene (cluster number, software used for clustering and information about other genes present in the same cluster) for all experiments can be obtained through the "Gene Query" (Figure 2).

\section{Raw data system analysis module}

This module has "Data and Cluster Query" options and "Data visualization" which is both a query and visualization option. "Data Query" (Figure 3) provides gene expression information at the level of signal intensities for single or multiple genes in all experiments. "Cluster Query" (Figure 3) - unique to RETINOBASE, provides 


\begin{tabular}{|c|c|c|}
\hline 0 & $\begin{array}{l}\text { Experiment details } \\
\text { Sample details }\end{array}$ & $\begin{array}{l}\text { EXPERIMIENT: This link provides the user with all the experiment details that are present in the RETINOBASE. Further a link is provided } \\
\text { to pubmed to those experiments whose data is derived from published articles }\end{array}$ \\
\hline 0 & Gene Information & $\begin{array}{l}\text { SAMPLE: This link provides the user with all the sample detalls that are present in the RETINOBASE. Once the user in sample details } \\
\text { page, if user prefers to findout all the samples present in particular experment he can enter Experiment ID }\end{array}$ \\
\hline & $\begin{array}{l}\rightarrow \text { Gene Query } \\
\rightarrow \text { Ortholog Query } \\
\rightarrow \text { Blast Query }\end{array}$ & $\begin{array}{l}\text { Gene Information : This link provides the user with gene details. Click on Gene Query takes user to new page where the user can enter } \\
\text { either one Genename, Genesymbol, Affymetrix Probe Set ID or multiple Genenames, Genesymbols or Affymetrix probeset id separated by } \\
\text { space inorder to get the Gene information. Gene information can also be obtained through two other query options: Ortholog Query provides } \\
\text { gene information about orthologs in different species avalable in RETINOBASE. Second option to get gene information is through BLAST } \\
\text { queny option. }\end{array}$ \\
\hline 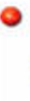 & $\begin{array}{l}\text { Raw Data System Analysis } \\
\rightarrow \text { Data Visualization }\end{array}$ & $\begin{array}{l}\text { Raw Data System Analysis: This option provides the user to access and visualize the data at the level of signal intensities and cluster } \\
\text { information present in the RETINOBASE. The user can either query data using Data Query, Cluster Query and Data Visulaization } \\
\text { option }\end{array}$ \\
\hline ? & $\begin{array}{l}\rightarrow \text { Data \& Cluster Query } \\
\text { Fold Change System Analysis }\end{array}$ & $\begin{array}{l}\text { Fold change Analysis: This option provides the user to access and visualize the data at the level of fold change. The user can query data } \\
\text { at this level using Ratio Query option }\end{array}$ \\
\hline & $\rightarrow$ Ratio Query & \\
\hline 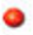 & User Manual & \\
\hline
\end{tabular}

\section{Figure I}

RETINOBASE home page. The home page of RETINOBASE [57] which has general information such as experiment and sample details. Specific query options are shown as in the database.

information about expression patterns of related genes across various conditions and genetic backgrounds. It also identifies any two given genes in the same cluster in one or more experiments. Apart from the above mentioned query options, RETINOBASE also provides a user-friendly transcriptomic data visualization tool that was developed to allow retinal biologists to graphically analyse gene expression profiles across all the experiments. A user can choose the experiment, chip, gene and analysis software to be used in a step-by-step process, following which the related samples can be labelled and organized for an easy comparison through histograms or radar-graph representations (Figure 4). This step-by-step process effectively increases querying speed, which in turn allows faster retrieval of specific data from large volumes of gene expression information. Additional information concerning the number of Probe Sets for a gene on a given chip, the normalization software used to obtain the signal intensities and the quality control report of the experiment are also provided.

\section{Fold change system analysis module}

Gene expression information at the level of fold change is provided for single or multiple genes in one or more experiments. In addition, "Ratio Query" supports a specialized query that permits retrieval of all genes from one or more experiments having a fold change greater and/or less than a given criteria.

\section{Downloading results and user manual}

In order to allow users to further compare and interpret data, the results from all querying modules available in RETINOBASE can be downloaded in the comma separated value (.CSV) file format using the "Download results" option.

A user manual is also available on the home page of RETINOBASE and it would provide a detailed description of the utilities.

\section{Case study: Use of meta-analysis tools in RETINOBASE}

In order to demonstrate the utility of RETINOBASE, we undertook a case study to identify novel genes that may have a potential role in retinal function. In the experiment "Targeting of GFP to newborn rods by $\mathrm{Nrl}$ promoter and temporal expression profiling of flow-sorted photoreceptors" (experiment 7 in RETINOBASE) it was elegantly demonstrated that $\mathrm{Nrl}$ (neural retina leucine zipper) is a key regulator of photoreceptor differentiation in mammals [17]. We first performed cluster analysis using the "Signal intensity or Cluster query" tool in RETINOBASE by providing $\mathrm{Nrl}$ as the gene symbol and then retrieved the resulting clusters. In agreement with the original study by Akimoto et al.,, our "cluster query" found Rho (rhodopsin), Nr2e3 (nuclear receptor subfamily 2, group E, member 3) and Pde6b (phosphodiesterase 6B, cGMP-specific, rod, beta) in the same cluster as $\mathrm{Nrl}$ in 4 out of 5 possible combinations (1. RMA normalized data and K- 
Gene Information

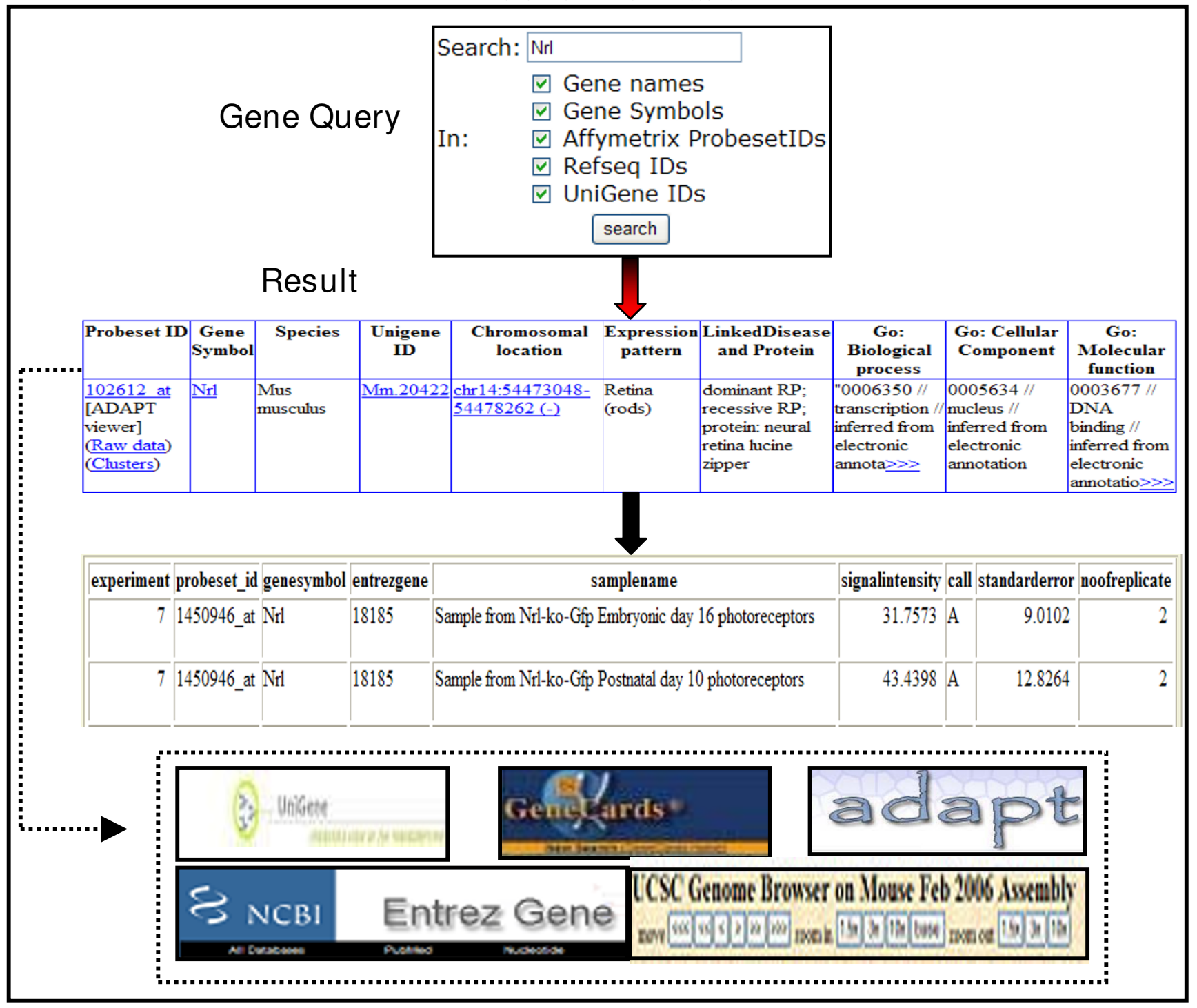

\section{Figure 2}

RETINOBASE Queries. A "Gene Query" yields information such as Unigene ID, chromosomal location, Entrez gene, expression pattern, linked diseases and gene ontology. The thick black arrow indicates that raw data and cluster information can be accessed directly from a "Gene Query" output, and the dotted line indicates links to external databases.

means clustering with TMEV, 2. RMA normalized data, Kmeans clustering with FASABI, 3. dChip normalized data, K-means clustering with TMEV, 4. dChip normalized data, K-means clustering with FASABI and 5. dChip normalized data, clustering with mixture model), confirming that genes specific for rods are coregulated with $\mathrm{Nrl}$. In addition, Gnat1 (guanine nucleotide binding protein (G protein), alpha transducing activity polypeptide 1), a gene implicated in congenital stationary night blindness [54], was also found in the same cluster in all 5 cluster combinations mentioned above, confirming its role in retinal function. This suggests that Gnat1 is also coregulated with $\mathrm{Nrl}$ in retina. Based on the similar coexpression profiles in wild type mouse retina at time points corresponding to embryonic day 16, post natal day 2, 6, 10 and 28 (Figure 5 ), we further identified a novel gene that is likely to be implicated in regulating retinal differentiation, namely D6Wsu176e (DNA segment, Chr 6, Wayne State University 176, expressed), described as being expressed in the outer nuclear layer of neural retina [55]. The RETINOBASE "Ortholog query" for D6Wsu176e points to the human ortholog, FAM $3 C$, that is involved in cell differen- 


\section{Raw Data System Analysis}

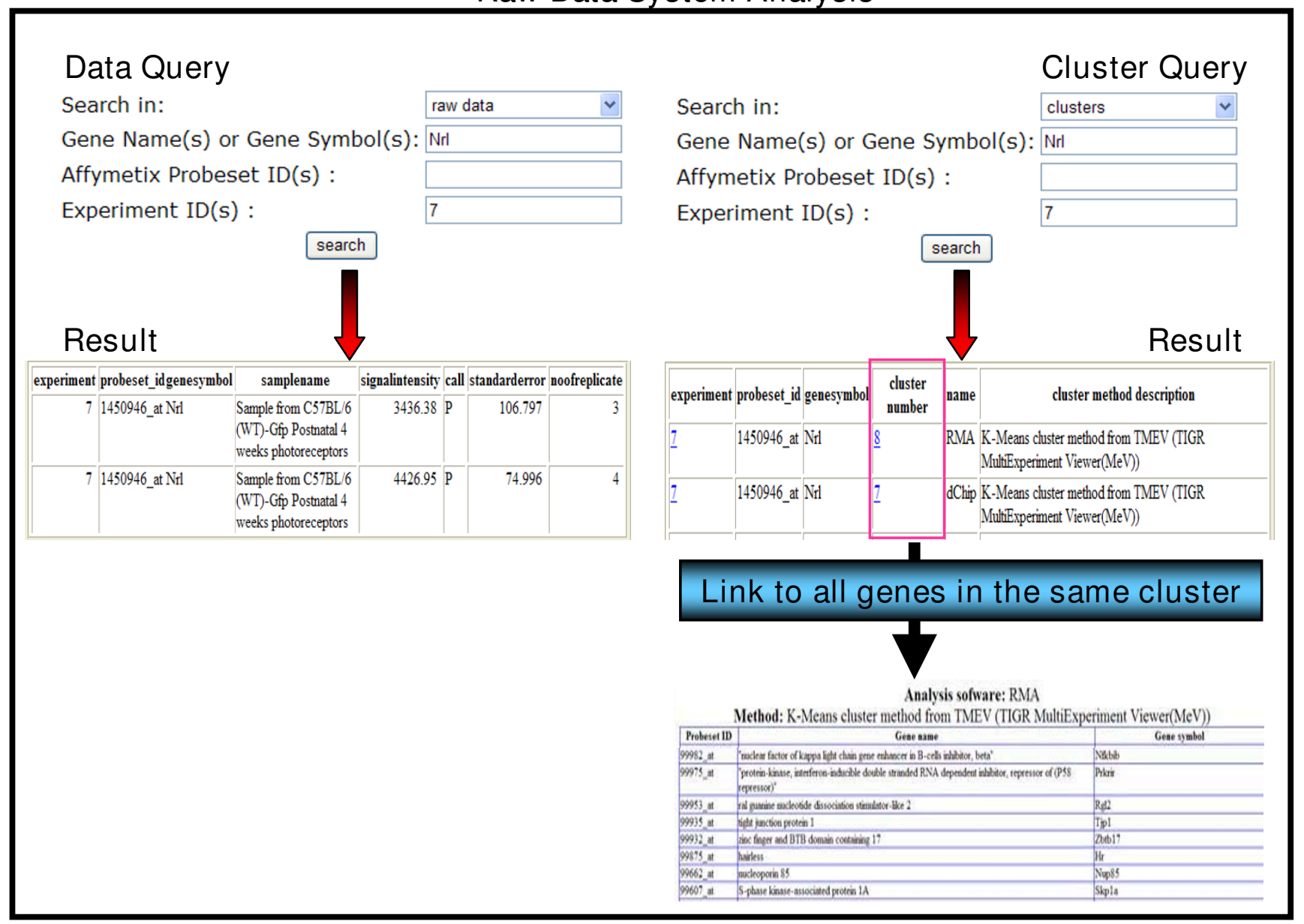

Figure 3

Data and Cluster Query options. Data and cluster query results for the NRL gene in experiment 7 [ I7]: "Targeting GFP to new born by NRL promoter and temporal expression profiling of flow-sorted photoreceptors". The user can subsequently obtain all genes present in the given cluster.

tiation and proliferation during inner ear embryogenesis [56]. With its known function in cell differentiation and its presence in the same cluster as $\mathrm{Nrl}$ in 3 out of 5 of the above mentioned clustering combinations, D6Wsu176e may be an interesting candidate for studying rod differentiation. We further went on to check whether $\mathrm{Nrl}$, Rho, Gnat1 and D6Wsu176e genes are coexpressed (present in the same cluster) in other experiments present in RETINOBASE, in particular checking experiment 12 (Gene expression patterns in the retina of rds mice treated with $\mathrm{CNTF} / \mathrm{rAAV}$ virus and non-treated after 60 days of injection) (GEO: GSE4756) and experiment 14 (Biological characterization of gene response in Rpe65-/- mouse model of Leber's congenital amaurosis during progression of the disease) [21]. In these two experiments the four genes mentioned above were present in the same cluster indicating that they might be coregulated. This case study illustrates how RETINOBASE facilitates hypothesis testing for the biologist, and demonstrates how to generate novel hypotheses regarding retinal function and finally, how to identify potential novel targets for human retinopathies.

\section{Future directions}

RETINOBASE is under constant development, including addition of new experiments when available. In addition, data from proprietary experiments can be accessed on approval by individual researchers and will be made generally available after publication. Several functional enhancements are also planned for the future. We will continue to refine and update RETINOBASE with respect to data retrieval, mining and visualization options. Direct upload and meta-analysis options will also be provided. 


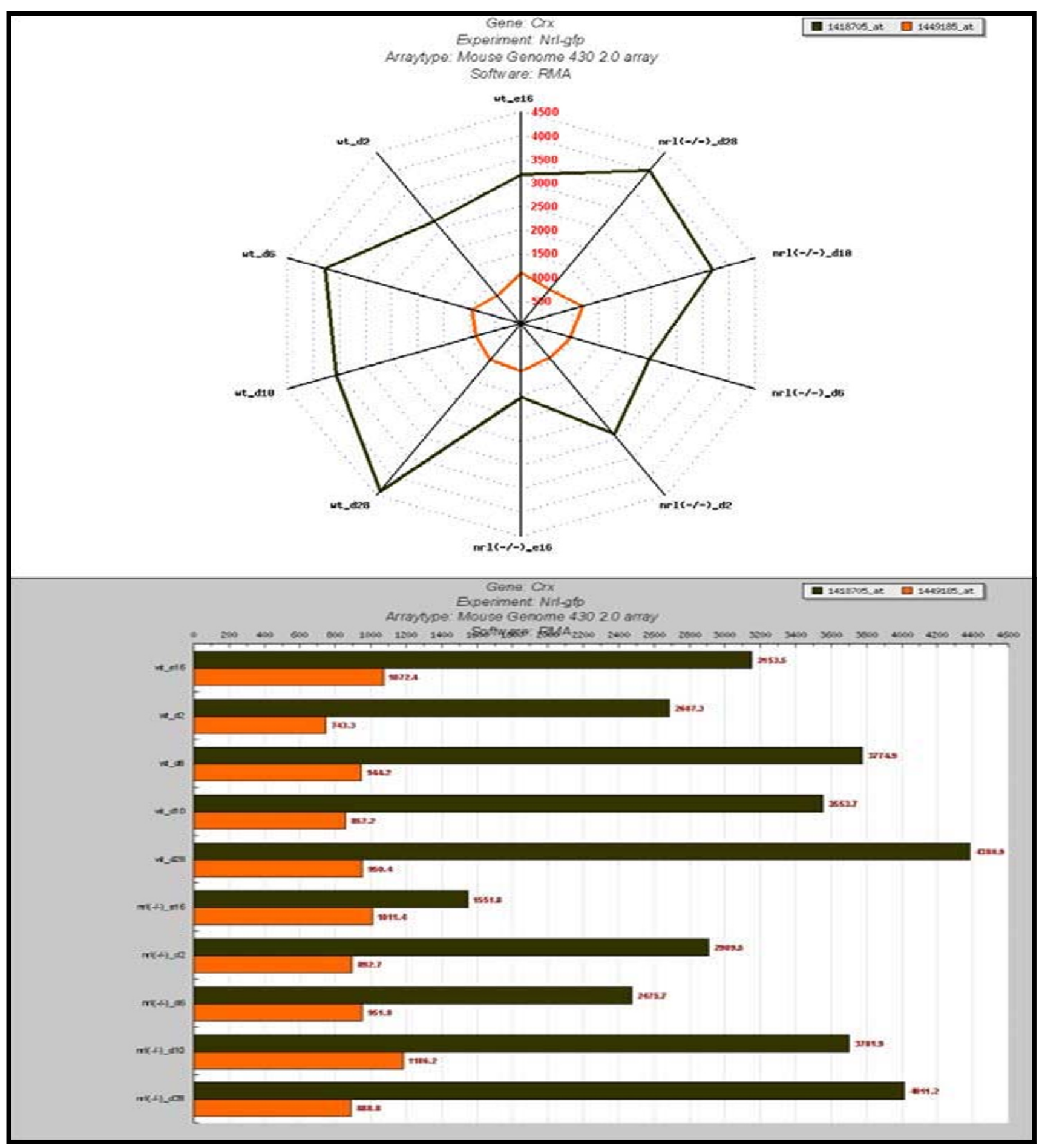

Figure 4

Data visualization. Expression profile of two Probe Sets of cone-rod homeobox containing gene (CRX) in the experiment 7 [17]: "Targeting GFP to new born by NRL promoter and temporal expression profiling of flow-sorted photoreceptors". Data is represented as radar plots on the top panel and as histograms in the bottom panel. 


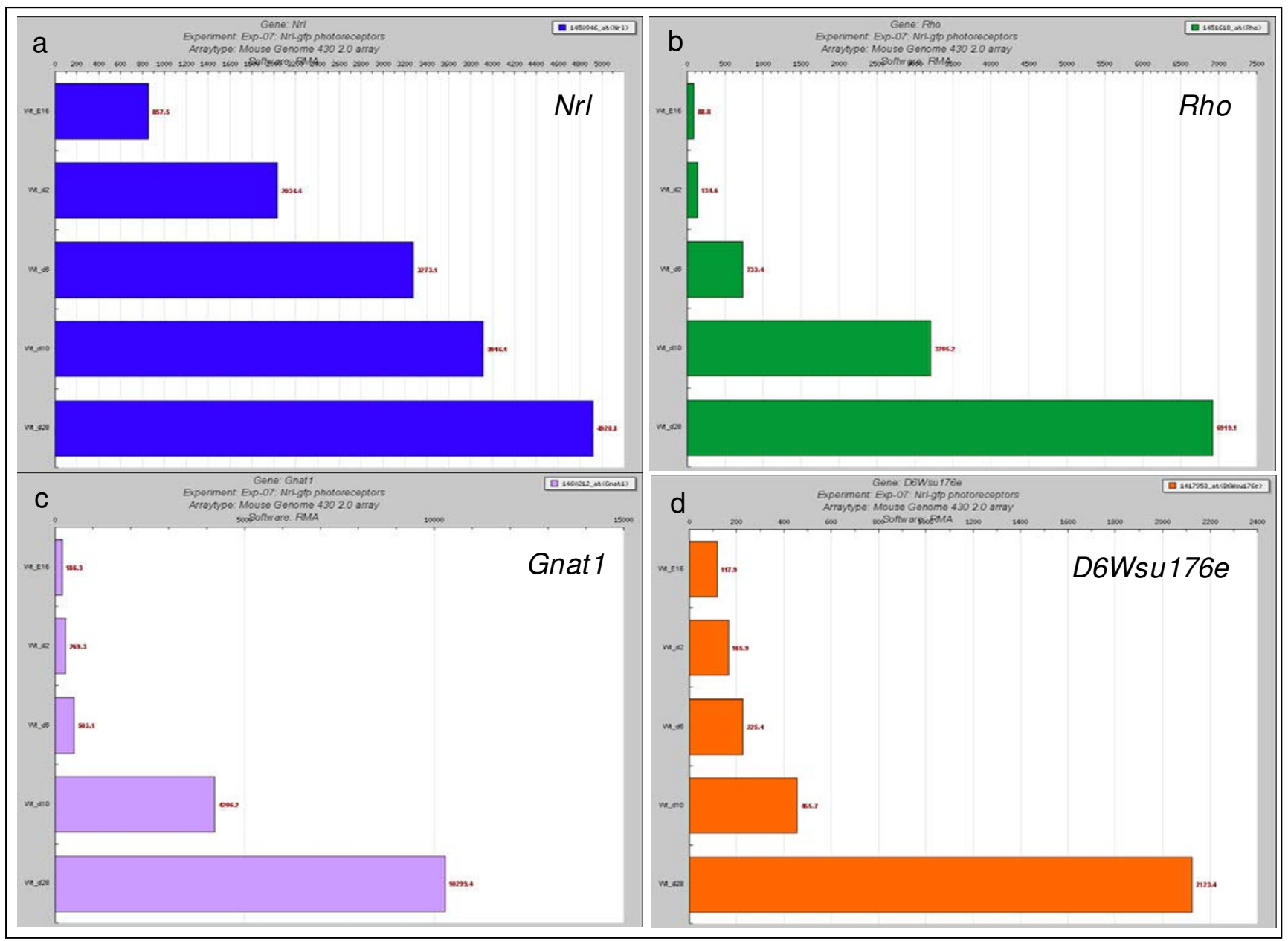

Figure 5

Expression levels (normalised signal intensities) of Nrl. (a) Rho, (b) Gnatl, (c) D6Wsu I76e, and (d) at embryonic day 16, post natal day 2, 6, 10 and 28 in experiment 7 [17].

\section{Conclusion}

RETINOBASE has been developed to store, analyse, visualize and compare retinal-related data in order to provide insights into retinal gene expression in various mouse models and other organisms under diverse conditions. Our database, with different types of query options and powerful visualization tools, allows comprehensive analysis of biological mechanisms/pathways of the retina in normal and diseased conditions. We demonstrated by means of a case study how novel genes such as D6Wsu176e (which potentially play an important role in retinal differentiation and development) can be identified using the meta analysis tools incorporated in RETINOBASE. With the addition of new experiments the variety of hypothesis testing options will continuously increase, providing biologists with a valuable tool to gain a better understanding of the retina.

\section{Availability and requirements}

The RETINOBASE can be accessed at [57]. All users must register (name and email address) to obtain a username and password.

\section{Authors' contributions}

$\mathrm{RK}$ is involved in database design and development, data analysis, design of the user interface and prepared the manuscript. NG, GB and RR developed the web services and database back end. LP is involved in testing various querying tools. WR is involved in data analysis and helped to draft the manuscript. TL participated in the design of the user interface. OP was involved in overall design of the project and in drafting the manuscript.

\section{Acknowledgements}

We would like to thank Naomi Berdugo for valuable suggestions, as well as "beta tester" users of the RETINOBASE, for their valuable suggestions. We thank Julie Thompson for proofreading the manuscript. This work was sup- 
ported by the European Retinal Research Training Network (RETNET) MRTN-CT-2003-504003, EVI-GENORET LSHG-CT-2005-5 I 2036, CNRS, INSERM and University of Louis Pasteur (ULP), Strasbourg, France.

\section{References}

I. Masland $\mathrm{RH}$ : The fundamental plan of the retina. Nat Neurosc 200I, 4(9):877-886.

2. Pittler S], Baehr W: Identification of a nonsense mutation in the rod photoreceptor cGMP phosphodiesterase beta-subunit gene of the rd mouse. Proc Natl Acad Sci USA 1991, 88(19):8322-8326.

3. Akhmedov NB, Piriev NI, Chang B, Rapoport AL, Hawes NL, Nishina PM, Nusinowitz S, Heckenlively JR, Roderick TH, Kozak CA, et al:: A deletion in a photoreceptor-specific nuclear receptor mRNA causes retinal degeneration in the rd7 mouse. Proc Natl Acad Sci USA 2000, 97( I 0):555I-5556.

4. Pang JJ, Chang B, Hawes NL, Hurd RE, Davisson MT, Li J, Noorwez SM, Malhotra R, McDowell JH, Kaushal S, et al:: Retinal degeneration I 2 (rd I 2): a new, spontaneously arising mouse model for human Leber congenital amaurosis (LCA). Mol Vis 2005, I I:I52-162.

5. Barrett T, Troup DB, Wilhite SE, Ledoux P, Rudnev D, Evangelista C Kim IF, Soboleva A, Tomashevsky M, Edgar R: NCBI GEO: mining tens of millions of expression profiles - database and tools update. Nucleic Acids Res 2007:D760-765.

6. Parkinson $H$, Kapushesky M, Shojatalab M, Abeygunawardena $N$, Coulson R, Farne A, Holloway E, Kolesnykov N, Lilja P, Lukk M, et al.: ArrayExpress - a public database of microarray experiments and gene expression profiles. Nucleic Acids Res 2007:D747-750.

7. Kato K, Yamashita R, Matoba R, Monden M, Noguchi S, Takagi T, Nakai K: Cancer gene expression database (CGED): a database for gene expression profiling with accompanying clinical information of human cancer tissues. Nucleic Acids Res 2005:D533-536.

8. Shah V, Sridhar S, Beane J, Brody JS, Spira A: SIEGE: Smoking Induced Epithelial Gene Expression Database. Nucleic Acids Res 2005:D573-579.

9. Su Al, Cooke MP, Ching KA, Hakak Y, Walker JR, Wiltshire T, Orth AP, Vega RG, Sapinoso LM, Moqrich A, et al:: Large-scale analysis of the human and mouse transcriptomes. Proc Natl Acad Sc USA 2002, 99(7):4465-4470.

10. Irizarry RA, Hobbs B, Collin F, Beazer-Barclay YD, Antonellis KJ, Scherf U, Speed TP: Exploration, normalization, and summaries of high density oligonucleotide array probe level data. Biostatistics 2003, 4(2):249-264.

II. Li C, Wong WH: Model-based analysis of oligonucleotide arrays: expression index computation and outlier detection. Proc Natl Acad Sci USA 200I, 98(I):31-36.

12. Hubbell E, Liu WM, Mei R: Robust estimators for expression analysis. Bioinformatics 2002, I 8(I 2): I585-I592.

13. Hartigan JAWM: A K-Means Clustering Algorithm. Applied Statistics 1979, 28(I): 100-108.

14. Medvedovic M, Sivaganesan S: Bayesian infinite mixture model based clustering of gene expression profiles. Bioinformatics 2002, I 8(9): I | 94-| 206

15. Saal LH, Troein C, Vallon-Christersson J, Gruvberger S, Borg A Peterson C: BioArray Software Environment (BASE): a platform for comprehensive management and analysis of microarray data. Genome Biol 2002, 3(8):SOFTWARE0003.

16. Brazma A, Hingamp P, Quackenbush J, Sherlock G, Spellman P Stoeckert C, Aach J, Ansorge W, Ball CA, Causton HC, et al.: Minimum information about a microarray experiment (MIAME)toward standards for microarray data. Nat Genet 2001, 29(4):365-37I.

17. Akimoto $M$, Cheng $H$, Zhu D, Brzezinski JA, Khanna R, Filippova E, Oh EC, Jing $Y$, Linares JL, Brooks $M$, et al:: Targeting of GFP to newborn rods by $\mathrm{Nrl}$ promoter and temporal expression profiling of flow-sorted photoreceptors. Proc Natl Acad Sci USA 2006, I 03( I 0):3890-3895

18. Yoshida S, Mears AJ, Friedman JS, Carter T, He S, Oh E, Jing Y, Farjo R, Fleury G, Barlow $C$, et al:: Expression profiling of the developing and mature Nrl-/- mouse retina: identification of retinal disease candidates and transcriptional regulatory targets of NrI. Hum Mol Genet 2004, I3( I 4): |487-| 503.
19. Chen J, Rattner A, Nathans J: The rod photoreceptor-specific nuclear receptor $\mathrm{Nr} 2 \mathrm{e} 3$ represses transcription of multiple cone-specific genes. J Neurosci 2005, 25(I): I I8-I 29

20. Liu J, Huang Q, Higdon J, Liu W, Xie T, Yamashita T, Cheon K, Cheng C, Zuo J: Distinct gene expression profiles and reduced JNK signaling in retinitis pigmentosa caused by RPI mutations. Hum Mol Genet 2005, I 4( I9):2945-2958.

21. Cottet S, Michaut L, Boisset G, Schlecht U, Gehring W, Schorderet DF: Biological characterization of gene response in Rpe65-/mouse model of Leber's congenital amaurosis during progression of the disease. Faseb J 2006, 20( I 2):2036-2049.

22. Vazquez-Chona F, Song BK, Geisert EE Jr: Temporal changes in gene expression after injury in the rat retina. Invest Ophthalmol Vis Sci 2004, 45(8):2737-2746.

23. Cheng H, Aleman TS, Cideciyan AV, Khanna R, Jacobson SG, Swaroop $A$ : In vivo function of the orphan nuclear receptor NR2E3 in establishing photoreceptor identity during mammalian retinal development. Hum Mol Genet 2006, I 5( I 7):2588-2602.

24. Gerhardinger C, Costa MB, Coulombe MC, Toth I, Hoehn T, Grosu $\mathrm{P}$ : Expression of acute-phase response proteins in retinal Muller cells in diabetes. Invest Ophthalmol Vis Sci 2005 46(I):349-357

25. Steele MR, Inman DM, Calkins DJ, Horner PJ, Vetter ML: Microarray analysis of retinal gene expression in the DBA/2J model of glaucoma. Invest Ophthalmol Vis Sci 2006, 47(3):977-985.

26. Cameron DA, Gentile KL, Middleton FA, Yurco P: Gene expression profiles of intact and regenerating zebrafish retina. Mol Vis 2005, I I:775-79|

27. Abou-Sleymane G, Chalmel F, Helmlinger D, Lardenois A, Thibault C, Weber C, Merienne K, Mandel JL, Poch O, Devys D, et al: Polyglutamine expansion causes neurodegeneration by altering the neuronal differentiation program. Hum Mol Genet 2006 , I 5(5):69|-703.

28. Kirwan RP, Leonard MO, Murphy M, Clark AF, O'Brien Cl: Transforming growth factor-beta-regulated gene transcription and protein expression in human GFAP-negative lamina cribrosa cells. Glia 2005, 52(4):309-324.

29. Zhang J, Gray J, Wu L, Leone G, Rowan S, Cepko CL, Zhu X, Craft $C M$, Dyer MA: Rb regulates proliferation and rod photoreceptor development in the mouse retina. Nat Genet 2004, 36(4):35I-360.

30. Leung YF, Ma P, Dowling JE: Gene expression profiling of zebrafish embryonic retinal pigment epithelium in vivo. Invest Ophthalmol Vis Sci 2007, 48(2):88I-890.

31. Carter TA, Greenhall JA, Yoshida S, Fuchs S, Helton R, Swaroop A Lockhart DJ, Barlow C: Mechanisms of aging in senescenceaccelerated mice. Genome Biol 2005, 6(6):R48.

32. Michaut L, Flister S, Neeb M, White KP, Certa U, Gehring W]: Analysis of the eye developmental pathway in Drosophila using DNA microarrays. Proc Natl Acad Sci USA 2003 , I 00(7):4024-4029.

33. Velculescu VE, Zhang L, Vogelstein B, Kinzler KW: Serial analysis of gene expression. Science 1995, 270(5235):484-487.

34. Diehn JJ, Diehn M, Marmor MF, Brown PO: Differential gene expression in anatomical compartments of the human eye. Genome Biol 2005, 6(9):R74.

35. Blackshaw S, Harpavat S, Trimarchi J, Cai L, Huang H, Kuo WP, Weber G, Lee K, Fraioli RE, Cho SH, et al.: Genomic analysis of mouse retinal development. PLoS Biol 2004, 2(9):E247.

36. The Affymetrix website [http://www.affymetrix.com/]

37. The Retinal information network [http://www.sph.uth.tmc.edu/ Retnet/]

38. The R statistical package [http://www.r-project.org]

39. Gentleman RC, Carey V], Bates DM, Bolstad B, Dettling M, Dudoit S, Ellis B, Gautier L, Ge Y, Gentry J, et al: Bioconductor: open software development for computational biology and bioinformatics. Genome Biol 2004, 5( I 0):R80.

40. Wicker N, Dembele D, Raffelsberger W, Poch O: Density of points clustering, application to transcriptomic data analysis. Nucleic Acids Res 2002, 30( I 8):3992-4000.

4I. Soukas A, Cohen P, Socci ND, Friedman JM: Leptin-specific patterns of gene expression in white adipose tissue. Genes Dev 2000, I4(8):963-980.

42. Saeed Al, Bhagabati NK, Braisted JC, Liang W, Sharov V, Howe EA, Li J, Thiagarajan M, White JA, Quackenbush J: TM4 microarray software suite. Methods Enzymol 2006, 4 I I:I34-I93. 
43. Datta S, Datta S: Evaluation of clustering algorithms for gene expression data. BMC Bioinformatics 2006, 7(Suppl 4):SI7.

44. Yeung KY, Haynor DR, Ruzzo WL: Validating clustering for gene expression data. Bioinformatics 200I, I7(4):309-3I8.

45. Sharan R, Maron-Katz A, Shamir R: CLICK and EXPANDER: a system for clustering and visualizing gene expression data. Bioinformatics 2003, I9(14): I787-1799.

46. Kohonen T: Self-Organizing Maps. 3rd edition. Springer-Verlag Berlin Hiedelberg New York; 200I.

47. Wilson CL, Miller CJ: Simpleaffy: a BioConductor package for Affymetrix Quality Control and data analysis. Bioinformatics 2005, 2 I(18):3683-3685.

48. Raffelsberger W, Krause Y, Moulinier L, Kieffer D, Morand AL, Brino L, Poch O: RReportGenerator: Automatic reports from routine statistical analysis using R. Bioinformatics 2007.

49. The GeneCards [http://www.genecards.org]

50. The NCBI [http://www.ncbi.nlm.nih.gov]

5I. The UniGene [http://www.ncbi.nlm.nih.gov/sites/entrez?db=uni gene]

52. Leong HS, Yates T, Wilson C, Miller Cl: ADAPT: a database of affymetrix probesets and transcripts. Bioinformatics 2005, 2I(10):2552-2553.

53. The UCSC genome browser [http://genome.ucsc.edu/cgi-bin/ hgGateway]

54. Szabo V, Kreienkamp HJ, Rosenberg T, Gal A: p.GIn200Glu, a putative constitutively active mutant of rod alpha-transducin (GNATI) in autosomal dominant congenital stationary night blindness. Hum Mutat 2007, 28(7):74|-742.

55. Blackshaw S, Fraioli RE, Furukawa T, Cepko CL: Comprehensive analysis of photoreceptor gene expression and the identification of candidate retinal disease genes. Cell 200I, 107(5):579-589.

56. Pilipenko VV, Reece A, Choo DI, Greinwald JH Jr: Genomic organization and expression analysis of the murine Fam $3 \mathrm{c}$ gene. Gene 2004, 335: 159-168.

57. RETINOBASE [http://alnitak.u-strasbg.fr/RetinoBase/]

\section{Publish with Bio Med Central and every scientist can read your work free of charge}

"BioMed Central will be the most significant development for disseminating the results of biomedical research in our lifetime. "

Sir Paul Nurse, Cancer Research UK

Your research papers will be:

- available free of charge to the entire biomedical community

- peer reviewed and published immediately upon acceptance

- cited in PubMed and archived on PubMed Central

- yours - you keep the copyright

Submit your manuscript here:

http://www.biomedcentral.com/info/publishing_adv.asp 